\title{
Quando o apego às coisas se trata de síndroma de Diógenes: a propósito de um caso clínico
}

Albina Oliveira, ${ }^{1}$ Sophie Sousa, ${ }^{1}$ Susana Paiva ${ }^{2}$

\section{RESUMO}

Introdução: A síndroma de Diógenes é um distúrbio de comportamento típico dos idosos. Caracteriza-se pela rejeição dos padrões sociais, traduzida pelo descuido pessoal e habitacional, no isolamento social progressivo e no reduzido juízo crítico para o problema, associado à acumulação de objetos e lixo. Apesar de a investigação nesta área ainda ser escassa, cerca de um terço a metade destes indivíduos não apresenta qualquer patologia psiquiátrica concomitante.

Caso clínico: Mulher, 78 anos, solteira, a viver sozinha após morte da irmã há cerca de três anos, com o quarto ano de escolaridade. Sem antecedentes médico-cirúrgicos de relevo. Foi trazida, pela primeira vez, à consulta aberta por uma vizinha, que referia que a doente vivia em habitação sem condições mínimas de habitabilidade e salubridade, com cuidados de higiene semanais e fornecidos pela mesma. Para averiguação das condições de habitabilidade foi agendado domicílio, onde foi constatada a acumulação de objetos e detritos na habitação. Para o apoio da doente foi contactada a assistente social, tendo a utente recusado a sua entrada no domicílio. Foi então notificado o Ministério Público, que solicitou a sua referenciação para a consulta de psiquiatria para despiste de doença psiquiátrica subjacente.

Comentário: O envelhecimento da população é um fenómeno mundial, sendo considerado como uma conquista da longevidade. Apesar desta conquista, a necessidade de cuidado ao idoso é crescente e evidenciada quando ocorre compromisso da capacidade funcional, ao ponto de impedir o autocuidado, aumentando a responsabilidade sobre a família e sobre o sistema de saúde.

O grave isolamento associado à síndroma de Diógenes, numa condição de vida à margem da sociedade, torna difícil a deteção destas situações. Assim, a visita domiciliária assume um papel fulcral na deteção precoce desta patologia. Além disso, o médico de família, como prestador de cuidados de primeira linha, deve promover a integração da família/cuidadores nos cuidados a prestar a estes doentes.

Palavras-chave: Síndroma de Diógenes; Médico de Família; Abordagem Multidisciplinar.

\section{INTRODUÇÃO}

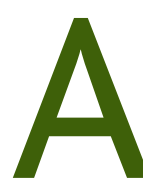
síndroma de Diógenes (SD) foi descrita, pela primeira vez, em 1966 por Macmillan e Shaw. No entanto, só em 1975 foi batizada com este nome, em memória ao filósofo grego do século IV a.C., Diógenes de Sinope, que acreditava na autossuficiência, desvalorizando todos os bens materiais e ajustando a sua existência ao mínimo vital.

Esta síndroma constitui uma condição clínica com importância crescente do ponto de vista social e de

'Médica Interna de Medicina Geral e Familiar

${ }^{2}$ Médica Especialista de Medicina Geral e Familiar

USF Oceanos, Unidade Local de Saúde de Matosinhos saúde pública pelas consequências que a ela estão associadas. ${ }^{1}$ Caracteriza-se pelo descuido significativo com a higiene pessoal, negligência com o asseio da própria moradia, isolamento social marcado e pela ausência de crítica para a situação. ${ }^{1-3}$ Está frequentemente associada a um comportamento paranóico, sendo frequente a ocorrência de colecionismo (como a acumulação de grandes quantidades de objetos inúteis, sem um propósito aparente). ${ }^{2}$

Epidemiologicamente, a SD caracteriza-se por afetar, sobretudo, mulheres (dois terços dos casos); em $84 \%$ dos casos são idosos (média de idades de 78 anos), dos quais $21 \%$ são muito idosos. São sobretudo indivíduos solteiros (44\%) ou viúvos (25\%), que habitam so- 
zinhos (64\%), em apartamento, em habitações com graves deficiências de habitabilidade, incapazes de manter relações e relutantes em receber qualquer ajuda. ${ }^{1}$

Neste caso clínico, o médico de família (MF), pela sua proximidade com a comunidade, teve um papel fundamental na suspeição e integração de todos os dados clínicos, sobretudo no que concerne à articulação com os prestadores de cuidados (família, vizinhos e assistente social) e com a especialidade de psiquiatria. O objetivo deste caso é alertar para a suspeição diagnóstica desta patologia, muitas vezes subdiagnosticada, mas associada ao prejuízo na capacidade de decisão, despoletando um estilo de vida negligente.

\section{CASO CLÍNICO}

DRO, género feminino, 78 anos, raça caucasiana, solteira, quarto ano de escolaridade. Natural e residente em Matosinhos. Vive sozinha desde a morte da irmã há cerca de três anos (família unitária); apresenta, no entanto, como pessoas de suporte, uma vizinha e o sobrinho. Não apresenta antecedentes patológicos, médicos ou cirúrgicos relevantes.

Pertencente a uma família com disfunção acentuada (dois pontos no APGAR familiar) e classe social de Graffar III (classe socioeconómica média).

\section{7 de agosto de 2013}

DRO, utente pouco frequentadora dos cuidados de saúde, foi, pela primeira vez, trazida a uma consulta aberta $^{4}$ pela vizinha. De acordo com a mesma, DRO vivia numa habitação sem condições mínimas de habitabilidade e salubridade, com cuidados de higiene semanais e fornecidos pela vizinha. A doente, contudo, negava estes factos, afirmando que as coisas que acumulava eram necessárias. Ao exame objetivo mostrava-se consciente, colaborante e orientada, auto e alopsiquicamente. Aspeto debilitado, embora relativamente cuidado. Humor neutro. Discurso lógico e coerente, sem alterações formais, com uma tonalidade ansiosa. Sem aparentes défices mnésicos (Mini Mental State Examination com 22 pontos de cotação), sem atividade heteróloga, sem ideias de teor auto ou heterodestrutivo. Ausência de crítica para a desadequação do comportamento. Foi agendado domicílio para ave- riguação das condições de habitabilidade, tendo sido solicitada a presença do sobrinho e da vizinha na visita domiciliária.

\section{9 de agosto de 2013}

Aquando do domicílio, constatou-se a acumulação de objetos e detritos no mesmo. O sobrinho referiu que desde sempre a tia, bem como a irmã falecida, tinham por hábito "acumular tralha em casa”. No entanto, após falecimento desta, verificou-se agravamento desse comportamento com acumulação de restos de comi$\mathrm{da}$, latas vazias e objetos deteriorados, que impediam o acesso à casa. Sublinhou que os vizinhos, por várias vezes, se tinham queixado do mau odor e do risco de incêndio. A doente, contudo, relativizava o relatado pelo sobrinho, referindo que apenas guardava os objetos por serem necessários. Foi recomendado ao sobrinho a necessidade de apoio diário à utente, com a integração em lar ou domicílio com apoio de terceiros. Foi também contactada a assistente social para orientação e agilização do processo.

\section{6 de outubro de 2013}

Cerca de um mês depois, a assistente social contactou o médico assistente, referindo que a doente tinha negado, por várias ocasiões, o acesso ao domicílio para averiguação das condições de habitabilidade. Nesse sentido, o caso foi notificado ao Ministério Público que, por sua vez, solicitou a sua referenciação para a consulta de psiquiatria para despiste de doença psiquiátrica subjacente. Informou também que a doente recusou a institucionalização e, por isso, o sobrinho tinha decidido que a doente passaria a residir numa pensão, com limpeza semanal do quarto e eliminação de todo o lixo que acumulasse.

\section{5 de novembro de 2013}

DRO teve consulta de psiquiatria a $24 / 10$ para avaliação do estado mental e da capacidade de reger a própria pessoa, após proposta de internamento compulsivo instituída pelo Ministério Público. Segundo informação da assistente social, a utente mantinha-se a residir numa pensão. Ficou também acordado que o sobrinho ficava responsável pela gestão dos bens de DRO, nomeadamente a sua reforma. Foi colocada, 
como hipótese mais provável, a síndroma de Diógenes, tendo sido solicitado estudo analítico (com avaliação nutricional), estudo imagiológico por tomografia computorizada crânioencefálica (TC-CE) e avaliação neuropsiquiátrica. Proposta terapêutica com quetiapina $25 \mathrm{mg}$ ao deitar. Contudo, a doente mostrou-se muito resistente a qualquer tipo de intervenção.

\section{$\mathbf{2 0}$ de fevereiro de $\mathbf{2 0 1 4}$}

Em consulta de reavaliação de psiquiatria, DRO mantinha as rotinas de recolha de pequenos objetos, que usava como adornos, mesmo após a instituição de quetiapina. Do estudo realizado não se verificaram alterações de relevo, nomeadamente no que diz respeito ao estudo de demências. Foi decidido manter tratamento com quetiapina e abordagem psicossocial, evitando alterações na rotina ou eventual institucionalização pelo potencial de agravamento em termos de morbimortalidade.

\section{COMENTÁRIO}

O envelhecimento da população é um fenómeno mundial, sendo considerado como uma conquista da longevidade. Apesar desta conquista, a necessidade de cuidado é crescente e evidenciada quando ocorre compromisso da capacidade funcional do idoso, ao ponto de impedir o autocuidado, aumentando a responsabilidade sobre a família e o sistema de saúde. ${ }^{8}$

O grave isolamento associado à SD, numa condição de vida à margem da sociedade, torna difícil a deteção destas situações. ${ }^{1}$ Geralmente, apenas se tornam públicas após deteção do fenómeno, geralmente pela vizinhança e apenas perante situações de grave risco para o próprio e para terceiros. ${ }^{1}$ Este caso ilustra esta realidade e a importância de suspeitar da SD perante certos sintomas inespecíficos, que podem ser, de outra forma, negligenciados. ${ }^{5}$

O MF, através do seu contacto continuado com famílias e idosos, está em posição privilegiada para identificar as situações, mas também para intervir preventivamente, reconhecendo as situações de risco e identificando estes idosos. Neste sentido, a consulta domiciliária assume um papel fulcral na deteção precoce desta patologia.

A consulta no domicílio, definida como «uma con- sulta direta, programada ou espontânea, na residência do utente, onde o seu MF avalia o seu estado de saúde, $o$ aconselha e trata, satisfazendo uma necessidade de cuidados assistenciais devido a uma impossibilidade de se deslocar ao gabinete médico", facilita, se realizada adequadamente, a compreensão e o cuidado ao doente, por propiciar o conhecimento de seus modos de vida, crenças, cultura e padrões de comportamento. ${ }^{9}$

O MF é, portanto, o pivô quer no reconhecimento atempado desta síndroma, quer no fornecimento dos cuidados de proximidade ao doente com SD, permitindo que estes doentes permaneçam o maior tempo possível no domicílio e evitando a multiplicação de cuidados. Como prestador de cuidados de primeira linha, é também responsável pela promoção, sensibilização e envolvimento da família e da vizinhança, assim como pela integração dos vários prestadores do cuidado (especialidade de psiquiatria, unidade de cuidados na comunidade e rede de apoio social).

O diagnóstico e o tratamento destes doentes são muito complexos. Este caso ilustra um caso clínico de SD primário, que se relaciona com uma atitude hostil do indivíduo perante o mundo, sem manifestação psicopatológica relevante. Apresenta-se em indivíduos com traços de personalidade pré-mórbidos (são geralmente pessoas independentes, excêntricas, agressivas) que, perante acontecimentos vitais stressantes (luto, reforma, solidão e doenças somáticas), causam um círculo vicioso que origina um estilo de vida isolado com abandono das regras sociais básicas e recusa de ajuda. ${ }^{1,5}$ Por sua vez, a SD secundária coexiste com um diagnóstico neuropsiquiátrico (alcoolismo, esquizofrenia, depressão e demência) com influência direta no comportamento do indivíduo. ${ }^{1,7}$

Frequentemente a primeira intervenção é realizada em situação de crise, na maioria dos casos a pedido da vizinhança pela inconveniência ou potencial risco que a situação gera. ${ }^{10} \mathrm{~A}$ ausência de consciência associada à deterioração social do doente faz com que o prognóstico na comunidade seja negativo. Por outro lado, estão descritas altas taxas de mortalidade após internamento em hospital ou instituições sociais, embora os resultados de diferentes estudos na área sejam discordantes. $^{2,10}$ 
Assim, várias podem ser as limitações para os cuidados a fornecer a estes indivíduos: a relutância em aceitar ajuda, a negação que se trata de um problema de saúde e a dificuldade na intervenção, uma vez que a remoção excessiva dos objetos, geralmente, está associada a uma angústia considerável, não diminuindo o risco de o doente voltar a acumular. Acrescido a isto, não existe legislação que proteja o doente ou a comunidade envolvente.

Numa perspetiva sociointerventiva levantam-se inúmeras questões, dilemas éticos e obstáculos que assentam na urgência de buscar melhor compreensão destes doentes: equilíbrio entre o princípio de autonomia e o princípio da beneficência e a capacidade de um continuum estreito entre os direitos individuais com a responsabilidade para e com a comunidade.

\section{AGRADECIMENTOS}

As autoras agradecem à Dra. Irene Lopes pelo cuidado na revisão do artigo.

\section{REFERÊNCIAS BIBLIOGRÁFICAS}

1. Almeida R, Ribeiro $O$. Síndrome de Diógenes: revisão sistemática da literatura [Diogenes syndrome: systematic literature review]. Rev Port Saúde Pública. 2012;30(1):89-99. Portuguese

2. Stumpf BP, Rocha FL. Síndrome de Diógenes [Diogenes syndrome]. J Bras Psiquiatr. 2010;59(2):156-9. Portuguese

3. Biswas P, Ganguly A, Bala S, Nag F, Choudhary N, Sen S. Diogenes syndrome: a case report. Case Rep Dermatol Med. 2013;2013:ID595192.

4. Missão para os Cuidados de Saúde Primários. Consulta aberta: consulta de agudos, não programada versus consulta aberta no hospital e centro de saúde [Internet]. Lisboa: Administração Central do Sistema de Saúde; 2007. Available from: http://www.acss.min-saude.pt/Portals/0/Consulta_Aberta_MCSP_20071213.pdf

5. Irvine JD, Nwachukwu K. Recognizing Diogenes syndrome: a case report. BMC Res Notes. 2014;7:276.
6. Carrato Vaz E, Martínez Amorós R. Síndrome de Diógenes: a propósito de un caso [Diogenes syndrome: a case report]. Rev Asoc Esp Neuropsiq. 2010;3(107):489-95. Spanish

7. Amanullah S, Oomman SK, Datta SS. Diogenes syndrome revisited. German J Psychiatry. 2009;12(1):38-44.

8. Aires M, Paz AA. Necessidades de cuidados aos idosos no domicílio no contexto da estratégia de saúde da família. Rev Gaúcha Enferm. 2008;29(1):83-9.

9. Cruz MM, Bourget MM. A visita domiciliária na estratégia de saúde da família: conhecendo as percepções das famílias [Home visiting in the family health strategy: investigating families' perceptions]. Saúde Soc. São Paulo. 2010;19(3):605-13. Portuguese

10. Soler Ros JJ, Lucha Fernández V, Palomar Llatas F, Fornes Pujalte B, Muñoz Máñez $V$, Sierra Talamantes $C$. Sindrome de diógenes y sus cuidados estandarizados (primera parte). Enferm Dermatol. 2010;4(10):814.

11. Cerezo Ramirez N, Palma Gois JA. O síndrome de Diógenes [Diógenes syndrome]. Psilogos. 2006;3(2):51-6. Portuguese

12. Frank C, Misiaszek B. Approach to hoarding in family medicine: beyond reality television. Can Fam Physician. 2012;58(10):1087-91.

13. Badr A, Hossain A, lqbal J. Diogenes syndrome: when self-neglect is nearly life threatening. Clin Geriatr. 2005;13(8):10-3.

14. Cipriani G, Lucetti C, Vedovello $M$, Nuti A. Diogenes syndrome in patients suffering from dementia. Dialogues Clin Neurosci. 2012;14(4):455-60.

\section{CONFLITO DE INTERESSES}

As autoras declaram não ter conflitos de interesses.

\section{ENDEREÇO PARA CORRESPONDÊNCIA}

Albina Maria Rodrigues Oliveira

R. Penedo do Azeite, n. ${ }^{\circ} 164$

Silvares São Martinho

4820-710 Fafe

E-mail: bi_oliveira@hotmail.com

Recebido em 11-08-2015

Aceite para publicação em 16-01-2016 


\section{ABSTRACT}

\section{THE DIOGENES SYNDROME: A CASE REPORT}

Introduction: The Diogenes syndrome is a behavior disorder of the elderly characterized by the rejection of social patterns, poor personal hygiene, progressive social isolation, and impaired judgment, associated with the accumulation of objects and trash. Research on this syndrome is scarce but one third to one half of affected individuals show no concomitant psychiatric disorders.

Clinical case: We present the case of a 78 year-old single female with a fourth grade education, living alone since her sister's death, three years previously. No relevant medical or surgical history was obtained. She was brought for the first time to a consultation by a neighbour, who stated that the patient was living in a house with poor hygienic conditions. The neighbour provided care once a week. A home visit was arranged to assess her living conditions. An accumulation of objects and waste was found in the patient's home. Evaluation by a social worker was requested but the patient refused her entry into her home. A court order was obtained for psychiatric assessment.

Comment: With the aging of the population there is a growing need for care of the elderly. This is clear when a decrease in the functional capacity of the elderly prevents self-care. This increases the responsibility of the family and the health care system. Severe isolation associated with Diogenes syndrome and a life on the margins of society, make detection difficult in these situations. Home visits play a key role in the early detection of this condition. The family physician, as first-line care provider, should promote the integration of family and other caregivers in the care of these patients.

Keywords: Diogenes Syndrome; Family Physician; Multidisciplinary Approach. 